\title{
Bargaining power as moderator of the "delay costs effect" in supply chain negotiations
}

\author{
Susana Gago-Rodríguez ${ }^{\mathrm{a}}$, Gilberto Márquez-Illescas ${ }^{\mathrm{b}}$, Manuel Núñez-Nickel ${ }^{\mathrm{c}, *}$ \\ ${ }^{a}$ Universidad Pontifica Comillas - ICADE, Economics and Business Administration School, C/Alberto Aguilera, 23, 28015, Madrid, Spain \\ ${ }^{\mathrm{b}}$ University of Rhode Island, College of Business Administration, 7 Lippit Road Kingston, RI, 02881, USA \\ ${ }^{\text {c } U n i v e r s i d a d ~ C a r l o s ~ I I I ~ d e ~ M a d r i d, ~ B u s i n e s s ~ A d m i n i s t r a t i o n, ~ C / M a d r i d, ~ 126, ~ 28903, ~ G e t a f e, ~ M a d r i d, ~ S p a i n ~}$
}

\section{A R T I C L E I N F O}

\section{Keywords:}

Relative bargaining power

Delay costs

Initial bargaining gap

Supply chain negotiations

\begin{abstract}
A B S T R A C T
This paper explores the extent to which bargaining power asymmetries among supply chain members moderate the effect that the delay costs of the setting exert on negotiation outcomes. First, we propose that the influence of delay costs on the initial gap between the bargaining demands of sellers and buyers (i.e., initial bargaining gap) decreases when buyers have a bargaining power advantage over sellers. Second, we posit that this moderation effect reduces the indirect effect that the delay costs have on negotiation outcomes (via the initial bargaining gap). To test these notions, we conduct a $2 \times 2$ between-subjects experiment with undergraduate students from a large European university in which we manipulate the relative bargaining power and delay costs of the setting. We conduct our analysis with 292 observations. Our findings support our theoretical predictions. Specifically, results indicate that bargaining power moderates (i.e., reduces) the effect of the delay costs on negotiation processes by reducing their influence on the initial bargaining gap. Likewise, our analysis shows that because more powerful buyers are less likely to modify their behavior as a result of the delay costs, they face a higher risk of obtaining suboptimal bargaining profits.
\end{abstract}

\section{Introduction}

Prior behavioral research on accounting and psychology exploring buyer-seller cooperative negotiations finds that buyers that have more bargaining power than their counterparties (i.e., sellers) usually demand and obtain a larger slice of the bargaining pie (e.g., De Dreu and Van Kleef, 2004; Van den Abbeele et al., 2009). In this study, we expand this research line by exploring how the relative bargaining power of buyers (i.e., in relation to sellers) moderates the extent to which they take into consideration negotiation costs when making their bargaining decisions. In particular, we claim that the extent to which the delay costs of the bargaining setting align the initial bargaining demands of sellers and buyers (i.e., sellers' initial offer and buyers' first counteroffers) and influence the outcomes of negotiations decreases when buyers have higher relative bargaining power than sellers.

The delay costs of the bargaining setting refer to the profit losses derived from the length of the negotiation (Cross, 1969). ${ }^{1}$ In general, as the delay costs of the setting accumulate faster (i.e., higher delay costs), rational negotiators will tend to use a less aggressive bargaining approach and will align their demands with their counterparties so as to have shorter negotiations (e.g., Grossman and Perry, 1986). Therefore, in settings with higher delay costs the difference between the initial demands of sellers and buyers (hereafter "initial bargaining gap") is likely to be smaller. Because initial offers inform negotiators of their counterparties' aspirations and general bargaining approach (e.g., Galinsky, 2004; Thompson, 2004), we expect the initial bargaining gap to also exert an important influence on the negotiation process. These notions suggest that the delay costs are likely to influence the outcomes of negotiations indirectly through the initial bargaining gap. Our theoretical framework posits that the extent to which the delay costs reduces the initial bargaining gap and exert an indirect effect on negotiation outcomes decreases when buyers hold a bargaining power advantage over sellers. Because relative bargaining power makes negotiators perceive a higher control over negotiation outcomes (Fast et al., 2009)

\footnotetext{
* Corresponding author.

E-mail address: mnunez@emp.uc3m.es (M. Núñez-Nickel).

1 There are multiple reasons for these profit losses, such as negotiators' inter-temporal preferences, the speed at which the consumer's interest in the negotiated product is eroded, contractual penalizations (e.g., due to late delivery), the threat of entry of new competitors (Srivastava et al., 2000), or even by more classical types such as financial or opportunity costs (Arnold, 2015).
} 
and lead them to underweight other environmental factors when making decisions (Galinsky et al., 2008), we expect more powerful buyers to be less prone to aligning their initial demands with those of the sellers. In other words, we propose that the degree to which the delay costs of the setting reduce the initial bargaining gap (i.e., align the initial demands of sellers and buyers) decreases when the buyers have higher relative bargaining power than sellers. As a result of this, we posit that buyers' bargaining power will reduce the indirect effect that the delay costs exert on the duration of negotiations and buyers' overall bargaining profits. $^{2}$

To test our theoretical expectations, we conduct a $2 \times 2$ betweensubjects experiment simulating a sequential buyer-seller negotiation in which we manipulate buyers' relative bargaining power (i.e., higher or equal in relation to sellers) and the delay costs (i.e., low or high) of the setting. In the setting, only buyers know the size of the bargaining pie, and they are allowed to share this information with sellers if they want to. We consider this setting to be an appropriate test of our hypothesis because its noncooperative nature provides a natural context in which the potential effects of bargaining power asymmetries are likely to affect buyers' decisions. In the same vein, using this specific setting allows us to develop hypotheses based on solid prior theoretical notions on the role of delay costs on bargaining processes and compare our work with prior behavioral research on negotiations (e.g., Grossman and Perry, 1986; Srivastava, 2001). Overall, as expected, our findings indicate that delay costs influence the extent to which negotiators' initial demands align with their counterparties, and this effect is moderated (i.e., reduced) by their relative bargaining power. Likewise, we find evidence suggesting that this moderation effect has consequences for the duration of negotiations and bargaining profits.

This study expands current accounting and business research exploring the effect of relative bargaining power and/or negotiation costs on negotiators' behavior and bargaining outcomes in two different ways. First, we expand the experimental accounting literature addressing the effects of relative bargaining power in supply chain negotiations (e.g., McCracken et al., 2011; Drake and Haka, 2008; Van den Abbeele et al., 2009; Chang et al., 2013; Masschelein et al., 2012) by showing that relative bargaining power not only promotes a distributive bargaining approach but it also reduces the extent to which negotiators consider other environmental factors into their decision-making process. In this way, when a negotiator is in a disadvantageous bargaining power position, she should not expect the powerful counterparty's behavior to be flexible as a result of other environmental factors, such as the delay costs. Or conversely, when negotiators are in an advantageous bargaining power situation, they should objectively evaluate the delay costs in order to avoid making excessively risky or overconfident decisions that may lead to suboptimal outcomes or even to a compromise of future interactions with their counterparty. Second, we contribute to the accounting literature exploring the way in which negotiation costs influence negotiators' behavior (e.g., Arnold, 2015). Specifically, we show that the extent to which negotiation costs influence negotiators' behavior and decisions depends on other factors, such as their relative bargaining power. Management and cost accounting researchers should consider these kinds of moderating effects when exploring how agents elaborate their cost-benefit analysis in different business situations. This

\footnotetext{
${ }^{2}$ A real-life example from market competition, in which the bargaining environment is determined by delay costs and bargaining power, could be the negotiations that Walmart holds with its different suppliers of different kinds of products. During 2015, Walmart decided to negotiate a price reduction with its suppliers in order to re-gain market share (Pettypiece and Townsend, 2015). The longer the negotiation, the larger Walmart's opportunity cost (e.g., loss in revenues) of not being competitive in the market. According to the news, less powerful suppliers accepted Walmart's conditions relatively quick; however, more powerful suppliers like Procter \& Gamble decided to enter into a longer negotiation.
}

is especially important in buyer-seller negotiations because these bargaining processes are often about business opportunities where the passage of time is costly (Cross, 1969; Srivastava et al., 2000), but it might also contribute to new insights on managers' answers to first offers by auditors where the timing and the power asymmetry are fundamental variables (Cheng et al., 2017; Sanchez et al., 2007). Third, although the effect of the difference between the initial demands of sellers and buyers (i.e., initial bargaining gap) has not previously been studied by accounting research on supply chain negotiations, our findings indicate that it may play an important role. Specifically, our analysis indicates that the initial bargaining gap acts as a process variable that significantly mediates the effect of bargaining power and delay costs on negotiation outcomes. This suggests that the initial bargaining gap effectively informs buyers' initial perceptions about the negotiation environment (e.g., bargaining power and delay costs) to the sellers, and this information exerts a significant influence on negotiation outcomes.

\section{Theory and hypothesis}

\subsection{Critical theoretical concepts}

Before developing theoretical predictions, we provide a brief theoretical insight into three critical notions for this study: delay costs, relative bargaining power, and the specific bargaining setting in our analysis. The term "delay costs" refers to the profit losses (i.e., both in monetary terms and the loss of utility derived from the postponement of consumption) derived from the passage of time (Cross, 1969). In this matter, delay costs are usually represented by a discount factor that indicates the degree to which earlier agreements are preferred over later agreements. This discount factor will depend, in general, on the sensitivity of the negotiation profits to the passage of time. Factors such as inter-temporal preferences, the speed at which the consumer's interest in the negotiated product is eroded, contractual penalizations (e.g., due to late delivery), the threat of entry of new competitors (Srivastava et al., 2000), or the existence of any other financial or opportunity cost (Arnold, 2015) may increase the delay costs of the setting. When negotiation-related profits decrease slowly (quickly) over time, buyers will discount future payoffs at a lower (higher) rate and, hence, their penalization for delaying agreements will be lower (higher). This rationale implies that the costs of engaging in longer negotiations are higher in settings with higher delay costs. As a consequence, in these kinds of settings buyers are likely to be more interested in reaching agreements earlier (e.g., Cramton, 1992). ${ }^{3}$

For the purposes of this study, we use a dependence-based notion of relative bargaining power developed within social exchange theory. This theory proposes that a buyer's relative bargaining power (i.e., buyer's capacity to influence the seller's actions) is a function of her relative dependency on the seller (e.g., Emerson, 1962). Hence, those buyers that possess more valuable alternatives than their trading partners (i.e., sellers) would be less dependent and therefore more powerful (e.g., Emerson, 1976; Wolfe and Mcginn, 2005). We adopt this notion of relative bargaining power as being consistent with previous accounting and economic research in dyadic negotiations, both in experimental and

\footnotetext{
${ }^{3}$ A related research stream explores the influence of time pressure on negotiators' behavior. This research line does not assume that the size of the bargaining pie shrinks every round but gives negotiators a deadline (i.e., certain number of rounds) to reach an agreement (e.g., Smith et al., 1982; De Dreu, 2003). In negotiations with delay costs every round is costly and negotiators experience losses from the initial rounds while in negotiations considering time pressure, negotiators can go several rounds without incurring any losses (i.e., the size of the bargaining pie does not decrease). We develop our theoretical predictions around the economic incentives generated by delay costs rather than on time pressure because our theoretical framework explores buyers' decision-making processes in the initial rounds of the negotiations.
} 
archival studies (e.g., Van den Abbeele et al., 2009; Schloetzer, 2012).

Finally, this study explores buyers' behavior in a noncooperative/ distributive sequential negotiation setting with one-sided (i.e., buyerside) asymmetric information, similar to the one proposed by Grossman and Perry (1986). In our setting, buyers are intermediaries that acquire a good from a seller in order to re-sell it to end consumers. ${ }^{4}$ Negotiations take place over the price of the good of interest. The seller's production cost is common knowledge to both negotiators. Buyers have a distribution cost per unit that is only known by them and the existence of this information asymmetry is common knowledge for both individuals. Therefore, sellers do not know the size of the bargaining pie (i. e., selling price to end consumers minus the accumulated costs of the supply chain) and are unable to calculate the relative split of the pie derived from buyers' offers. Buyers, in contrast, possess full information on these issues. The game consists of a series of offers and counteroffers, always started by the seller, that continues until an agreement is reached or any of the parties abandons the negotiation without reaching an agreement. When making a counteroffer, buyers are free to accompany it with private information revealing the size/split of the bargaining pie. In this setting, bargainers' gains diminish according to an equal and commonly known discount rate. If the process ends without an agreement, the parties' payoffs are equal to a certain value defined by their outside options.

\subsection{Delay costs, bargaining power, and initial bargaining gap}

Fig. 1 shows a summary of our theoretical propositions. Research on sequential bargaining suggests that the delay costs of the setting exert an important influence on negotiation outcomes (e.g., Grossman and Perry, 1986). This influence is composed by two different effects. The first is a mathematical or direct effect on the bargaining profits. In settings with higher delay costs, ceteris paribus, the cost of extending negotiations is higher than in settings with lower delay costs. Therefore, for the same final price and number of rounds negotiated, profits will be lower in settings with higher delay costs. This feature of sequential negotiations creates a systematic difference between the bargaining profits of negotiations conducted in settings with different levels of delay costs (in our case low and high delay costs). The second effect is the influence that the delay costs exert on negotiation outcomes by influencing the behavior of negotiators. In settings with higher delay costs, bargainers (i.e., sellers and buyers) are likely to be more interested in reaching earlier agreements (e.g., Grossman and Perry, 1986; Srivastava et al., 2000) and have lower demands (e.g., Zwick and Chen, 1999) than in settings with lower delay costs. Hence, in settings with higher delay costs, sellers tend to make less aggressive initial offers, and buyers tend to be more likely to accept those initial offers, or submit less aggressive counteroffers in case they reject them. In other words, in settings with higher delay costs, the gap between the initial bargaining positions of sellers and buyers (the initial bargaining gap hereafter) tends to be smaller. We consider that there is no scientific interest in exploring the first effect (i.e., mathematical effect of delay costs on profits). Therefore, although we empirically control for this first effect in our empirical analysis, our study focuses on the effect that delay costs exert on negotiation outcomes through the behavior of negotiators. For the purposes of our analysis, we refer to this behavioral effect as the "behavioral delay cost effect" or simply the "behavioral effect." More specifically, we investigate how differences in the relative bargaining power among negotiators influence this behavioral effect.

We expect that the extent to which the "behavioral delay costs effect" reduces the initial bargaining gap depends on the relative bargaining power status among negotiators. Negotiators holding a relative

\footnotetext{
${ }^{4}$ We could translate this same example to the relationship between two links in a supply chain, or the negotiation of transfer prices between departments of the same company.
}

bargaining power advantage over their counterparties are more likely to show higher aspirations, make higher demands, and give fewer concessions than negotiators bargaining under equal power conditions (e.g., Pinkley et al., 1994; De Dreu and Van Kleef, 2004). Moreover, relative bargaining power changes negotiators' perception about the overall negotiation environment, and therefore the extent to which they incorporate other environmental factors into their decision-making process. Specifically, negotiators with higher relative bargaining power are more optimistic about obtaining their desired outcomes (Anderson and Galinsky, 2006), more oriented toward risk-taking (Jordan et al., 2011), more prone to making overconfident decisions (Fast et al., 2012), and have a more exaggerated perception of control over outcomes (Fast et al., 2009). These notions suggest that buyers with a higher relative bargaining power (i.e., over sellers) may consider other situational factors to a lesser extent when making bargaining decisions (White and Neale, 1994; Galinsky et al., 2008). Therefore, we propose that the negative influence of delay costs on the initial bargaining gap will be reduced when buyers hold a relative bargaining power advantage.

We specifically propose the moderating role of buyers' bargaining power to occur on the initial bargaining gap (as opposed to subsequent bargaining gaps during the negotiation) because buyers have a better opportunity to communicate their "maximum" negotiation demands at the beginning of the negotiation. Prior literature suggests that in bilateral negotiations, the initial offers of each party establish the negotiation limits. Once these limits are established, counteroffers on each side tend to be more favorable to the counterparty with each subsequent interaction and, therefore, offers and counteroffers gradually converge over time (Backus et al., 2020). Intuitively, this notion suggests that once negotiation boundaries are set, both parties are likely to either stand firm or make concessions, but do not tend to go backward and ask for even greater concessions in a subsequent offer (i.e., the bargaining gaps are likely to get smaller over time). Based on these notions, we expect relative bargaining power to reduce the negative behavioral effect of the delay costs on buyers' demands in the initial bargaining gap because it is usually in this initial stage where buyers can communicate their maximum demands to the seller. These prior arguments motivate the following hypothesis:

H1. The negative behavioral influence of the delay costs on the initial bargaining gap is reduced when buyers hold a bargaining power advantage.

\subsection{The mediated moderation eff ;ect of buyers' bargaining power on the relation between delay costs, duration of negotiations, and bargaining profits}

As mentioned in the theoretical development of H1, in settings with higher delay costs, the initial bargaining demands of sellers and buyers tend to be more similar than in settings with lower delay costs. This similarity in the initial demands (or lower initial bargaining gap) facilitates earlier agreements. If the initial bargaining gap is equal to 0 , agreements are reached immediately. If the initial bargaining gap is positive, sellers will be more likely to settle when the initial bargaining gap is lower. Therefore, by reducing the initial bargaining gap, the delay costs of the setting are likely to reduce the duration of negotiations. In other words, the delay costs have a negative indirect effect on the duration of negotiations via the initial bargaining gap. Given that the behavioral effect of the delay costs on the initial bargaining gap is likely to be reduced when buyers hold a bargaining power advantage (i.e., $\mathrm{H} 1$ ), we expect the indirect behavioral effect of the delay costs on the duration of negotiations (via the initial bargaining gap) to be reduced when buyers hold a bargaining power advantage. We formalize these ideas with the following hypothesis:

H2. The negative indirect behavioral effect of the delay costs on the duration of negotiations (via the initial bargaining gap) is reduced when buyers hold a bargaining power advantage. 


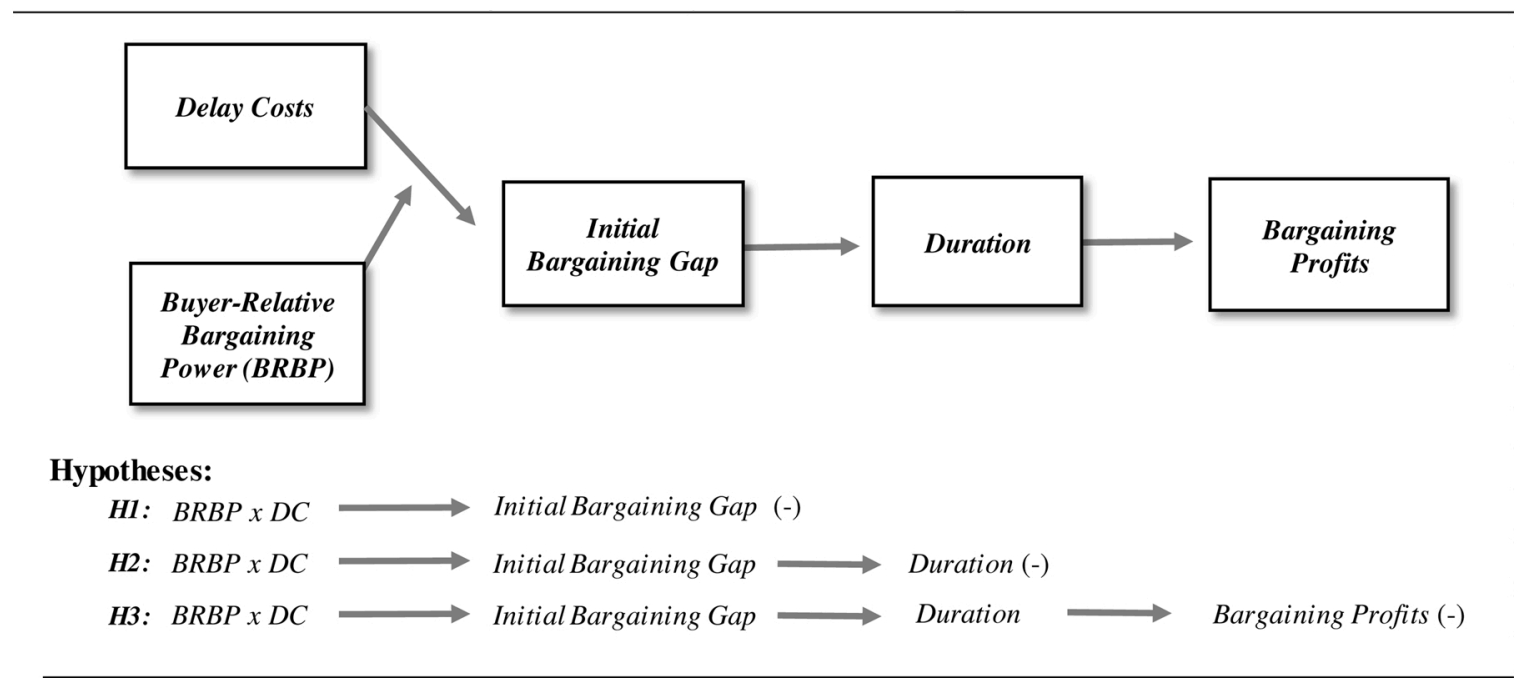

Fig. 1. Summarizes our hypotheses. The figure proposes that: a) The negative influence of the delay costs on the initial bargaining gap is reduced when buyers hold a bargaining power advantage (H1); b) The negative indirect effect of the delay costs on the duration of negotiations (via the initial bargaining gap) is reduced when buyers hold a bargaining power advantage. (H2); c) The positive indirect effect of the delay costs on buyers' profits (via the initial bargaining gap and the duration of negotiations) is reduced when buyers hold a bargaining power advantage (H3).

The reduction in the duration of negotiations driven by the behavioral effect of the delay costs is likely to influence buyers' profits because buyers are likely to make more profits when negotiations are shorter. Buyers' profits are higher if an acceptable price is agreed in the first round rather than in further rounds because in the first round the delay costs are equal to zero. Likewise, those buyers rejecting the initial offer and negotiating for a lower price would obtain higher profits if their first counteroffer is accepted immediately by the sellers than if the negotiations move to another round. As mentioned above, offers and counteroffers gradually converge over time because counteroffers on each side tend to be more favorable to the counterparty with each subsequent interaction (Backus et al., 2020). Hence, if a negotiation moves to another round, the accumulated delay costs will be higher but the price reduction that the buyers may obtain is likely to decrease (i.e., because sellers will try to reduce it by submitting a price above the one proposed by the buyer's first counteroffer). As a result, longer negotiations are likely to reduce buyers' bargaining profits.

Altogether, the arguments noted above indicate that the "behavioral delay costs effect" reduces the duration of negotiations, which may help buyers to obtain higher bargaining profits. In other words, the delay costs are likely to have a positive behavioral indirect effect on buyers' profits that flows sequentially through the initial bargaining gap and the duration of negotiations. Given that buyers' bargaining power reduces the "behavioral delay costs effect" on the initial bargaining gap (i.e., $\mathrm{H} 1$ ), we propose that buyers' relative bargaining power will also reduce the positive indirect behavioral effect of the delay costs on buyers' bargaining profits (via the initial bargaining gap and the duration of negotiations). We formalize this proposition with the following hypothesis:

H3. The positive indirect behavioral effect of the delay costs on buyers' profits (via the initial bargaining gap and the duration of negotiations) is reduced when buyers hold a bargaining power advantage.

\section{Method}

\subsection{Design of the experiment}

To test our hypotheses, we conducted a $2 \times 2$ between-subjects experiment in which we manipulated the relative bargaining power of buyers in relation to sellers (higher or equal) and the delay costs (high or low). Power was manipulated by informing the participants about the availability of their own outside options (e.g., Giebels et al., 2000; Pinkley et al., 1994) as well as giving some information on their counterparty (Wolfe and Mcginn, 2005). In the dyads in which buyers held a bargaining power advantage over the sellers, buyers were told that they had another option in the market with a value of 5 euros (Van den Abbeele et al., 2009) and that their counterparts considered them to be their top choice. Sellers were told that they did not have any other alternative transactions in the market, but buyers considered them their favorite option. In the equal power treatment, buyers and sellers were told that they did not have any other alternative transactions in the market but that they were the favorite option of their partner. In this case, the value of the outside option was fixed at 0 . The value of the external choices was treated as private information for each partner so as to achieve ecological validity (Wolfe and Mcginn, 2005).

Regarding the delay costs, we manipulated this concept by informing the participants that their benefits would be discounted by a factor equal to $d^{t-1}$, where $t$ accounts for the current round of the negotiation and $d$ is a parameter that measures the time-sensitivity of the business opportunity linked to the negotiation. In the same regard, we informed buyers and sellers that they would both have the same delay costs. ${ }^{5}$ To facilitate the participants' calculations, we provided them with a figure indicating the value of the discount factor at every negotiation round. Following previous research, the value of parameter $d$ was fixed at 0.90 for the low delay-cost group and at 0.60 for the high delay-cost group (e.g., Srivastava et al., 2000). ${ }^{6}$

\subsection{Negotiation task}

Participants negotiated in dyads (i.e., seller-buyer negotiations). The negotiation task of the experiment followed the structure of a noncooperative bargaining process with alternating offers and one-sided incomplete information as studied analytically by Grossman and Perry (1986) and tested experimentally by Srivastava et al. (2000) and

\footnotetext{
${ }^{5}$ Equal discount rates are a natural assumption following from the presence of efficient capital markets. If the trader's discount rates are different, the traders have an incentive for the one with the smaller discount rate to lend an arbitrarily large amount of money to the other (Cramton, 1992).

${ }^{6}$ In addition, to create a sense of trust among the dyad members, all participants were told that their counterparty had a good reputation in the market, and that they had completed successful transactions together in the past.
} 
Srivastava and Chakravarti (2009). ${ }^{7}$ To test our hypotheses, we enriched this general setting by introducing differences in the relative bargaining power among traders (given by outside options). ${ }^{8}$ More specifically, our experimental setting simulates a purchasing process between a seller and a buyer in which the costs of the seller are common knowledge to both negotiators but the cost information of the buyer is not observed by the seller (and both the buyer and seller know that the seller is not aware of it). The seller supplies a manufactured good with a unitary production cost, $C_{P}=€ 100$. The buyer is a retailer buying one unit of the good from the manufacturer at a price $P_{t}$ and reselling it to an end consumer at a fixed price, $P_{E C}=€ 150$. Both $C_{P}$ and $P_{E C}$ are the traders' common knowledge. The buyer, however, has a distribution cost $\left(C_{D}\right)$ of 10 euros per unit, which is known only by her. Thus, the seller is not able to calculate either the total size of the bargaining pie (i.e., $P_{E C}-C_{P}-C_{D}$ ) or the real split of the bargaining pie derived from any given offer. The bargaining continues sequentially over a series of infinite discrete periods of time. In the first period, the seller makes a price offer, $P_{1}$, and the buyer either accepts or rejects it. If the buyer accepts, the negotiation ends in the first period. However, if the buyer rejects this price, she will make a counteroffer, $P_{2}$, starting at a second stage (i.e., period two). When making a counteroffer, the buyer can also communicate any message (including her private cost information) with the seller. Offers and counteroffers continue until either an agreement is reached or any of the parties end the negotiation without reaching an agreement. In this last case, the parties' payoffs are equal to a certain value defined by their outside options. $^{9}$ In this experimental setting, the bargainers' gains diminish according to a commonly known discount rate equal to $d^{t-1}$. It is common knowledge to buyers and sellers that they both have the same discount rate. Considering these features, the benefits for each partner at any period $t$ of the negotiation are $\pi_{\text {Seller }}=\left(P_{t}-C_{P}\right) d^{t-1}$ and $\pi_{\text {Buyer }_{t}}=$ $\left(P_{E C}-C_{D}-P_{t}\right) d^{t-1}$.

\subsection{Participants and procedure}

Participants were recruited from management accounting undergraduate courses at an AACSB, AMBA, and ACCA accredited university in Europe. ${ }^{10}$ The experiment was conducted with 588 participants during one-hour experimental sessions. We randomly assigned participants to one of the four conditions (higher bargaining power-low delay costs, higher bargaining power-high delay costs, equal bargaining power-low delay costs, and equal bargaining power-high delay costs), to a role in the supply-chain relationship (buyer or seller), and to a specific dyad. Buyers and sellers were seated in different rooms to guarantee the anonymity of the negotiations. As a first step, participants received a brief explanation of the general purpose of the experiment, the possible payoffs, their information endowments, and their set of possible actions. They were then given $15 \mathrm{~min}$ to read the written

\footnotetext{
${ }^{7}$ We chose this specific setting because prior theoretical and experimental work suggests that in this specific setting, the delay costs might influence buyers' behavior, and indicates the relevance of offers and counter-offers as the main vessel through which information flows from the informed to the uninformed party (e.g., Grossman and Perry, 1986). These two notions constitute building blocks to elaborate our testable predictions.

${ }^{8}$ Similar to Srivastava and Chakravarti (2009), we allow communication among traders. However, different from this previous study, we allow buyers to share with the sellers any kind of information, including their private information.

9 As mentioned before, we give participants a notion about their own bargaining power and the bargaining power of their counterparty. We did not give them precise information so as to achieve ecological validity, as suggested by Wolfe and Mcginn (2005). This may create information asymmetries between the parties. In our statistical tests, we control for the effect of these information asymmetries on buyers' bargaining behavior.

${ }^{10}$ Approval to conduct these experiments was granted by the academic authority of the university where the experiment took place.
}

directions and ask any questions. Next, participants filled out a prenegotiation questionnaire that recorded their bargaining power perceptions and other general characteristics, such as their trust perception, age, gender, and professional experience. Once the negotiations were completed, participants filled out a post-negotiation questionnaire to check whether their perceptions of power and trust changed during the negotiation process. All offers, counteroffers, and information shared during a trade were written down on a negotiation sheet that was visible to both partners throughout the experiment. The communication of offers among negotiators was made through the aforementioned negotiation sheets. Given that buyers and sellers were seated in different rooms, the negotiation sheets were physically transported and delivered (by a research assistant) between rooms and among counterparties as needed. Finally, as a reward for participating in the experiment, subjects received a fixed payment of 0.25 points ${ }^{11}$ over their final grade (in their management accounting class) plus a variable payment of up to an additional 1.25 points contingent on their performance in the negotiation task (e.g., James and Cohen, 2004). The fixed payment offsets the effects of randomization and encouraged the participation of more risk-averse subjects (e.g., Heckman and Smith, 1995; Harrison et al., 2009). The variable payment encouraged the involvement of participants in the bargaining task. According to previous research, this difference between fixed and variable payments should be enough to assure the involvement of undergraduate students in the negotiation (Croson, 2005). Following this procedure, we collected information on 294 dyads. We dropped two dyads from the analysis because subjects did not provide enough complete information to conduct our statistical analysis. Therefore, our final sample contains information on the bargaining process of 292 dyads.

\subsection{Statistical methods and variables}

We conduct our empirical testing using the path analysis shown in Fig. 1. We test our first hypothesis with the sign and significance of the interaction term between Delay Costs and Buyer-Relative Bargaining Power in the model explaining Initial Bargaining Gap. To test the significance and sign of the indirect effects proposed in $\mathrm{H} 2$, and $\mathrm{H} 3$, we use bootstrapped $95 \%$ confidence intervals (e.g., Hayes, 2017). ${ }^{12}$ In Fig. 1, the variables Buyer-Relative Bargaining Power and Delay Costs indicate the conditions which participants were assigned in the experiment. The former takes a value of 1 if a buyer belongs to the higher relative bargaining power condition, and 0 otherwise. The latter takes a value of 1 if a buyer belongs to the high delay cost condition, and 0 otherwise. We use these two variables as the main explanatory variables to test our hypotheses.

We use different types of models in the different paths of Fig. 1, depending on the characteristics of the dependent variable. In this matter, we use a Tobit model to explore the joint effect of our experimental manipulations on the variable Initial Bargaining Gap. This specific model allows us to directly address the fact that the variable Initial Bargaining Gap is censored at 0 and a substantial fraction of the observations are at the lower limit (e.g., Lourenço, 2020; Lourenço et al., 2018). We calculate the variable Initial Bargaining Gap as the difference between sellers' initial offer and the buyers' first counteroffer. For the buyers accepting the sellers' initial offer, this variable takes a value of 0 . In other words, we assume that if the negotiation was closed in the first

\footnotetext{
11 The fixed payment was given to participants as a coupon at the end of the experiment, and they were informed of their variable reward the day after the experiment. The variable part of the reward (1.25 points) was allocated based on participants' performance during the negotiation. Specifically, we split the 1.25 points (deflated by the delay costs) based on the share of the bargaining pie obtained by each dyad member (i.e., seller and buyer).

12 The path model and the intervals were calculated using the commands gsem, nlcom, and bootstrap in STATA 15.1.
} 
round it is because the gap between the initial demands of buyers and sellers was close to 0. To explain the effect of Initial Bargaining Gap on Duration, we use an ordinary least squares (OLS) model. The variable Duration accounts for the natural logarithm of the total number of rounds needed to reach an agreement. ${ }^{13}$ We use the natural logarithm of the total rounds because this transformation is consistent with the non-linear way in which the delay costs accumulate as the number of rounds increase. ${ }^{14}$ The duration of negotiations is an important outcome since it indicates how efficient the negotiation is in terms of minimizing delay costs. Finally, to explain the relation between Initial Bargaining Gap and Bargaining Profits we use an OLS regression model consistent with the continuous nature of the endogenous variable (Bargaining Profits).

In our models, we include the variable Equal Monetary Payoff to control for negotiators' tendency to follow a bargaining strategy that is referred to as Equal Monetary Payoff or simply EMP (Srivastava et al., 2000). The EMP is a non-strategic model proposing that the negotiators tend to reach agreements in which they receive an equal split of the bargaining pie. Previous research on sequential bargaining indicates that the EMP represents an heuristic rule (or a focal point) that is a priori not related to our experimental treatments (i.e., delay costs and bargaining power) ${ }^{15}$ and that is likely to explain the outcomes of a significant number of negotiations (Srivastava et al., 2000). According to the EMP, the average buyer receiving the "equal-split" initial offer may be more likely to accept it. Hence, the EMP is likely to influence the initial bargaining gap by modifying buyers' propensity to accept sellers' initial offer (in which case the initial bargaining gap is zero). The variable Equal Monetary Payoff accounts for this effect. This variable takes a value of 1 if the seller's initial offer is 120 (the price that split the bargaining pie equally), and zero otherwise. Finally, given that experimental sessions occurred at diff ;erent times/days, and individuals self-selected into their sessions, our models include fixed session eff ;ects (i.e., Fréchette, 2012; Blay et al., 2019).

\section{Results}

\subsection{Summary of statistics and preliminary experimental findings}

Table 1 indicates that the average initial bargaining gap in our sample is 5.28 euros, with a range that goes from 0 to 36 euros. For around $50 \%$ of the observations, the variables Initial Bargaining Gap takes the value of 0 because these buyers accepted the seller's initial offer. Regarding the number of rounds, the average negotiation was closed after 1.73 rounds. The shortest negotiation was closed in the first round, and the longest one was closed after negotiating eight rounds. The distribution of the variable Bargaining Profits indicates that, on average, buyers obtained profits of 17.2 euros. However, the range of the variable shows that the buyer with the highest bargaining profits obtained 30 euros, while the buyer with the minimum bargaining profits obtained only 0.65 euros. The distribution of Equal Monetary Payoff suggests that around $30 \%$ of buyers received offers allowing sellers to keep $50 \%$ of the bargaining pie.

Table 2 shows the Pearson's (Spearman) pairwise correlation between the variables in our study. Consistent with our theoretical framework, Initial Bargaining Gap has a high and positive correlation

\footnotetext{
13 For the buyers in dyads that did not reach an agreement (i.e., 4 buyers), Duration refers to the round in which the negotiation was unilaterally finished by one of the parties. Likewise, for these buyers we calculate Bargaining Profits based on their outside options. In our additional analysis, we control for differences among negotiations that ended with and without an agreement.

${ }^{14}$ In the statistical summary and mean comparisons presented in tables 1 and 3 , respectively, we use the number of rounds (as opposed to the variable Duration) to facilitate the interpretation of the tables.

15 Consistent with this notion, we did not find a significant statistical relation between our experimental treatments and the variable Equal Monetary Payoff.
}

with Duration ( $r=0.77 ; r_{s}=0.93$ ), and a negative and significant correlation with Bargaining Profits $\left(\mathrm{r}=-0.52 ; \mathrm{r}_{\mathrm{s}}=-0.60\right)$. Likewise, we observe that Bargaining Profits is negatively correlated with Duration $(\mathrm{r}=-$ 0.59; $r_{s}=-0.60$ ). Finally, Equal Monetary Payoff is correlated with our three outcomes variables (i.e., Initial Bargaining Gap $\left[\mathrm{r}=-0.41 ; \mathrm{r}_{\mathrm{s}}=-0.50\right]$; Duration [ $\left.\mathrm{r}=-0.44 ; \mathrm{r}_{\mathrm{s}}=-0.47\right]$, and Bargaining Profits $\left[\mathrm{r}=-0.36 ; \mathrm{r}_{\mathrm{s}}=-\right.$ 0.53]), which is consistent with the EMP model. An analysis of the variance inflation factors (VIF) of individual variables in our analysis are low (i.e., lower than 4) and, thus, these correlations are unlikely to cause major problems in our experimental results.

Table 3 presents the means (and mean differences) and standard deviations (below) of our dependent variables (i.e., Initial Bargaining Gap, Duration, and Bargaining Benefits) in each of the four experimental conditions of the study. As seen in Table 3, the initial bargaining gap decreases with the delay costs. However, this decrease is three times higher when buyers negotiate under equal relative bargaining power conditions than when they hold a bargaining power advantage $(-2.34$ and -0.87 for equal and higher relative bargaining power). This provides preliminary support for our first hypotheses. Regarding the number of rounds, we observe that negotiations tend to be shorter when delay costs are higher, and this decrease in the number of rounds is smaller when buyers have a relative bargaining power advantage $(-0.65$ and -0.38 for equal and higher relative bargaining power). Finally, buyers' bargaining profits seem to be lower in settings with higher delay costs and this difference seems to be even larger when buyers have a bargaining power advantage (-1.51 and -2.52 for equal and higher relative bargaining power). Although these raw mean comparisons offer some preliminary insights, they do not control for other important factors influencing the dynamics of negotiations. Therefore, they provide a somewhat noisy picture of the influence that delay costs and relative bargaining power have on buyers' behavior and bargaining outcomes. In the next section, we present a formal and detailed statistical analysis explaining the relation between our experimental factors (i.e., Buyer-Relative Bargaining Power and Delay Costs) and our dependent variables (i.e., Initial Bargaining Gap, Duration, and Bargaining Profits).

\subsection{Main results}

Table 4 shows the results of our main analysis. Panel A shows the estimation of the different paths of the path model depicted in Fig. $1 .^{16}$ Model 1 presents the results of a Tobit model testing the joint effect of Buyer-Relative Bargaining Power and Delay Costs on Initial Bargaining Gap. Findings indicate that Delay Costs exert a negative and significant direct effect on Initial Bargaining Gap, while the direct effect of Buyer-Relative Bargaining Power is not significant. Consistent with our theoretical framework, the negative effect of Delay Costs on Initial Bargaining Gap is moderated in a positive and significant way by Buyer-Relative Bargaining Power (p-value $<0.05$ ). This suggests that the negative effect of the delay costs of the setting on the initial bargaining gap is reduced when buyers have a relative bargaining power advantage, which provides support for H1. Model 2 indicates that Initial Bargaining Gap exerts a positive direct effect on Duration (p-value $<0.01$ ). In this vein, on average, buyers extend the duration of negotiations when they enlarge the initial bargaining gap. To test the moderated mediation proposed in $\mathrm{H} 2$, we calculate the $95 \%$ bootstrapped confidence interval (BCI95\%) for the indirect effect of the interaction term between Buyer-Relative Bargaining Power and Delay Costs on Duration via Initial Bargaining Gap. Panel B of Table 4 indicates that this indirect effect is positive and significant

\footnotetext{
16 The complete path model was estimated using the gsem command in STATA 15.1. We used the command gsem because it allows us to model the effect of our experimental manipulations on the variable "Initial Bargaining Gap" using a Tobit model. As a robustness test, we also estimated the path model using the sem command, which uses OLS models at all stages of the path model. Results using both approaches are similar.
} 
Table 1

Summary of Statistics.

\begin{tabular}{|c|c|c|c|c|c|c|c|c|}
\hline Variable & $\mathbf{n}$ & Mean & S.D. & Min & 0.25 & Median & 0.75 & Max \\
\hline Initial Bargaining Gap & 292 & 5.28 & 7.43 & 0 & 0 & 0 & 10 & 36 \\
\hline Number of Rounds & 292 & 1.73 & 1.02 & 1 & 1 & 1 & 2 & 8 \\
\hline Bargaining Profits & 292 & 17.2 & 4.57 & 0.65 & 15 & 18 & 20 & 30 \\
\hline Equal Monetary Payoff & 292 & 0.29 & 0.46 & 0 & 0 & 0 & 1 & 1 \\
\hline
\end{tabular}

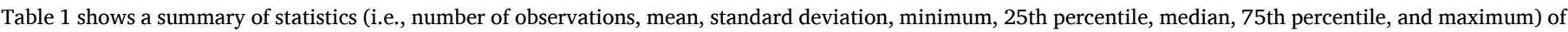

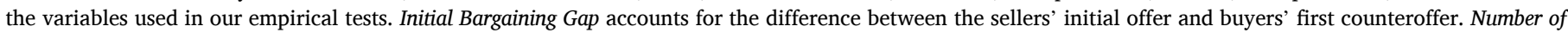

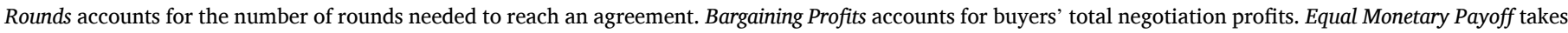
the value of 1 if the seller's initial offer is equal to the offer that splits the pie equally (i.e., 120), and 0 otherwise.

Table 2

Correlation in the sample of buyers submitting a counteroffer (292 obs.).

\begin{tabular}{|c|c|c|c|c|c|}
\hline \multicolumn{2}{|c|}{ Variables } & \multirow{2}{*}{$\begin{array}{l}1 \\
1\end{array}$} & \multirow{2}{*}{$\frac{2}{0.93^{* * *}}$} & \multirow{2}{*}{$\frac{3}{-0.60^{* * *}}$} & \multirow{2}{*}{$\frac{4}{-0.50^{* * *}}$} \\
\hline 1 & Initial Bargaining Gap & & & & \\
\hline 2 & Duration & $0.77 * * *$ & 1 & $-0.60 * * *$ & $-0.47 * * *$ \\
\hline 3 & Bargaining Profits & $-0.52^{* * *}$ & $-0.59 * * *$ & 1 & $0.53^{* * *}$ \\
\hline 4 & Equal Monetary Payoff & $-0.41 * * *$ & $-0.44 * * *$ & $0.36 * * *$ & 1 \\
\hline
\end{tabular}

Table 2 presents the Pearson (Spearman) Correlations above (below) the diagonal of the matrix. Correlations correspond to the sample of buyers who decided to reject the seller's initial offer and make a counteroffer. Initial Bargaining Gap accounts for the difference between the sellers' initial offer and buyers' first counteroffer. Duration accounts for the natural logarithm of the number of rounds needed to reach an agreement. Bargaining Profits accounts for buyers' total negotiation profits. Equal Monetary Payoff takes the value of 1 if the seller's initial offer is equal to the offer that splits the pie equally (i.e., 120), and zero otherwise. *, **, $* * *$ indicate significance at $10 \%, 5 \%$, and $1 \%$, respectively.

Table 3

Statistics by Experimental Conditions.

\begin{tabular}{|c|c|c|c|c|c|c|}
\hline & \multicolumn{3}{|c|}{$\begin{array}{l}\text { Equal Buyer-Relative } \\
\text { Bargaining Power }\end{array}$} & \multicolumn{3}{|c|}{$\begin{array}{l}\text { High Buyer-Relative Bargaining } \\
\text { Power }\end{array}$} \\
\hline & $\begin{array}{l}\text { Low } \\
\text { Delay } \\
\text { Costs } \\
\mathrm{n}=71\end{array}$ & $\begin{array}{l}\text { High } \\
\text { Delay } \\
\text { Cost } \\
\mathrm{n}=71\end{array}$ & Diff. & $\begin{array}{l}\text { Low } \\
\text { Delay } \\
\text { Costs } \\
\mathrm{n}=73\end{array}$ & $\begin{array}{l}\text { High } \\
\text { Delay } \\
\text { Costs } \\
\mathrm{n}=77\end{array}$ & Diff. \\
\hline \multirow[t]{2}{*}{$\begin{array}{l}\text { Initial } \\
\text { Bargaining } \\
\text { Gap }\end{array}$} & 6.41 & 4.07 & -2.34 & 5.77 & 4.90 & -0.87 \\
\hline & 8.13 & 6.94 & & 7.26 & 7.30 & \\
\hline \multirow[t]{2}{*}{$\begin{array}{l}\text { Number of } \\
\text { Rounds }\end{array}$} & 2.03 & 1.38 & -0.65 & 1.95 & 1.57 & -0.38 \\
\hline & 1.18 & 0.70 & & 1.17 & 0.83 & \\
\hline \multirow[t]{2}{*}{$\begin{array}{l}\text { Bargaining } \\
\text { Profits }\end{array}$} & 18.00 & 16.49 & -1.51 & 18.45 & 15.93 & -2.52 \\
\hline & 2.87 & 5.00 & & 3.38 & 5.85 & \\
\hline
\end{tabular}

Table 3 presents means (and mean differences) and standard deviations (below) of our dependent variables (i.e., Initial Bargaining Gap, Duration, and Bargaining Benefits) in each of the four experimental conditions of the study. Initial Bargaining Gap accounts for the difference between the sellers' initial offer and buyers' first counteroffer. Number of Rounds accounts for the number of rounds needed to reach an agreement. Bargaining Profits accounts for buyers' total negotiation profits.

(BCI95 \%: [0.039, 0.517]). Panel B also shows that the indirect effect of Delay Costs on Duration (via Initial Bargaining Gap) is negative and significant (BCI95 \%: [-0.519, -0.151]). This evidence suggests that, consistent with $\mathrm{H} 2$, the negative indirect effect that the delay costs of the setting exert on the duration of negotiations is reduced when buyers have a relative bargaining power advantage. Model 2 also provides some insights about the direct effect of our experimental treatments on Duration. In this matter, results show that the delay costs of the setting exert a direct negative effect on the duration of negotiations. These effects occur because the delay costs exert a negative effect on the bargaining gaps produced in each rounds of negotiations. However, as the
Table 4

Main Results.

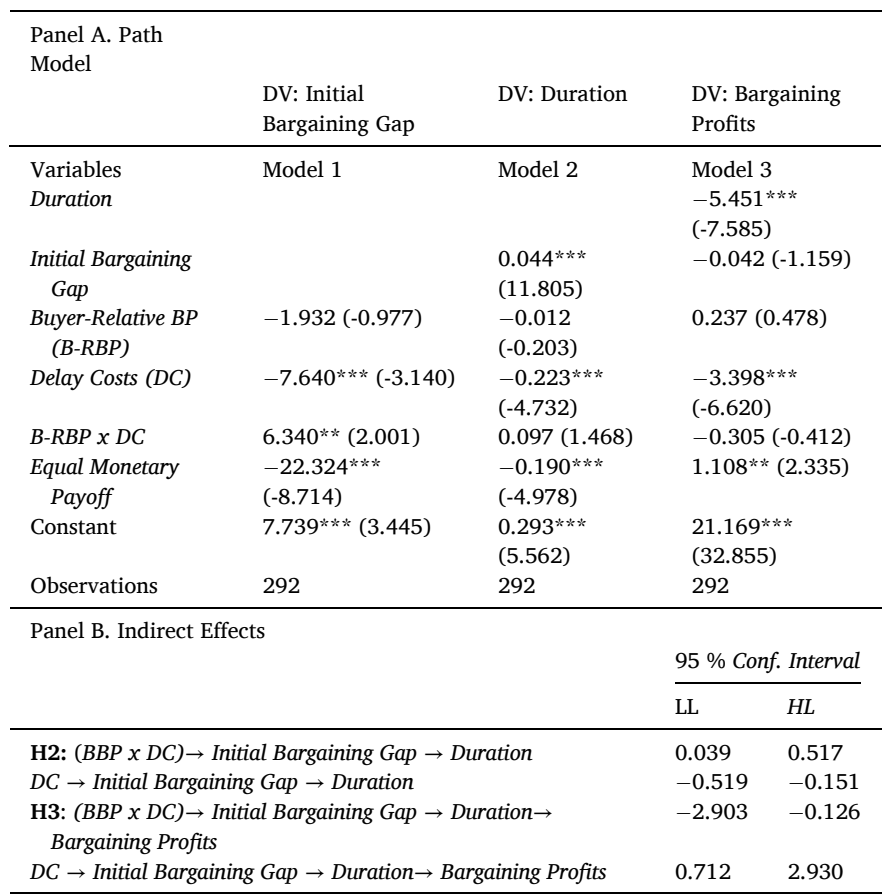

Table 4 presents our main results. Panel A shows estimated coefficients and tstatistics (in parenthesis below). Dependent variables of each model are indicated in the heading of each model. As explained in subsection 3.4, Model 1 is a Tobit model while models 2 and 3 are OLS models. Delay Costs takes a value of 1 if the buyers belong to the high delay costs condition and, 0 otherwise. BuyerRelative Bargaining Power takes a value of 1 if the buyers belong to the high relative bargaining power condition and, 0 otherwise. Initial Bargaining Gap accounts for the difference between the sellers' initial offer and buyers' first counteroffer. Duration accounts for the natural logarithm of the number of rounds needed to reach an agreement. Bargaining Profits accounts for buyers' total negotiation profits. Equal Monetary Payoff takes the value of 1 if the seller's initial offer is equal to the offer that splits the pie equally (i.e., 120), and zero otherwise. All models include session fixed-effects. All models are estimated simultaneously using the gsem command (with robust errors) in Stata 15.1. Panel B shows bootstrapped $95 \%$ confidence intervals assessing the indirect effects proposed in hypotheses $\mathrm{H} 2$, and H3. Confidence intervals are calculated using commands gsem, nlcom, and bootstrap (1000 repetitions) in Stata 15.1. Consistent with our directional hypotheses, Table 4 presents one-tailed pvalues/confidence intervals for the hypothesized effects, and two-tailed p-values otherwise. *, **, *** indicate significance at $10 \%, 5 \%$, and $1 \%$, respectively. 
model shows, this influence is not moderated by buyers' relative bargaining power. Likewise, we do not find any direct effect of BuyerRelative Bargaining Power on Duration. These findings are consistent with the idea that relative bargaining power is likely to influence negotiations mostly at the beginning of the negotiations. Model 3 indicates that Duration exerts a negative direct effect on Bargaining Profits (p-value $<0.01) .{ }^{17}$ That is, buyers obtain lower bargaining profits when they engage in longer negotiations. To test the moderated mediation proposed in $\mathrm{H} 3$, we calculate the $95 \%$ bootstrapped confidence interval (BCI95 \%) for the indirect effect of the interaction term between BuyerRelative Bargaining Power and Delay Costs on Bargaining Profits via the Initial Bargaining Gap and Duration. Panel B of Table 3 indicates that this indirect effect is negative and significant (BCI95 \%: [-2.903, -0.126]). Panel B also shows that the indirect effect of Delay Costs on Bargaining Profit (via Initial Bargaining Gap and Duration) is positive and significant (MCCI95 \%: [0.712, 2.930]). This evidence suggests that the positive indirect behavioral effect of the delay costs on buyers' bargaining profits (via the initial bargaining gap and the duration of negotiations) is moderated by the buyer's relative bargaining power. Model 3 also shows that, as explained in the development of $\mathrm{H1}$ (subsection 2.2), the delay costs have a direct effect (i.e., mathematical effect) on buyers' bargaining profits. However, findings indicate this effect is not moderated by the bargaining power. In the same fashion, we find that Buyer-Relative Bargaining Power does not affect Bargaining Profits directly. Consistent with our theoretical framework, these results suggest that Buyer-Relative Bargaining Power influences Bargaining Profits in an indirect way, by moderating the effect of the delay costs on the initial bargaining gap. ${ }^{18}$ Fig. 2 presents a summarized version of our main findings.

Finally, in concordance with the EMP model, we find that Equal Monetary Payoff exerts a significant effect on the outcome variables of interest. This result supports the idea that the negotiators' decisions are somewhat driven by non-strategic heuristic rules. Overall, results suggest that when buyers receive an "equal-split" initial offer, the initial bargaining gap decreases, agreements are reached sooner, and negotiation profits are likely to be higher. Moreover, around one-third of the negotiations in our sample started with an initial offer to split the bargaining pie equally, and $93 \%$ of these offers were accepted immediately. These findings coincide with previous research on sequential negotiations highlighting the predictive power of the EMP model and the importance of taking it into account when analyzing negotiators' behavior (e.g., Srivastava et al., 2000). Consistent with this notion, we

\footnotetext{
17 Model 3 indicates that Initial Bargaining Gap does not exert a significant influence on Bargaining Profits ( $\mathrm{p}>0.10$ ). In an additional analysis, we found that Initial Bargaining Gap exerts a negative and significant effect on Bargaining Profits ( $\mathrm{p}$-value $=0.01$ ). However, this influence disappears ( $\mathrm{p}$-value $>0.10$ ) when Duration is included in the model. This result suggests that, consistent with our theoretical framework, the duration of negotiations fully mediates the effect of the initial bargaining gap in buyers' bargaining profits. This "partial result" is not shown in our path model, and hence, we do not report it in our main results. Nevertheless, we provide a more detailed explanation of this result in subsection 4.3 (Additional Tests).

${ }^{18}$ We also ran an additional analysis to test whether the moderating effect of relative bargaining power affects the most basic decision that buyers make in the negotiation process: accepting sellers' initial counteroffer or rejecting it and making a counteroffer. For this purpose, we ran the set of models presented in Table 4 replacing Initial Bargaining Gap with buyers' accept/reject decision as a dependent variable. The results of this analysis corroborate our main findings. Likewise, as a robustness test, we ran our empirical models controlling for some additional outcome or process variables. Specifically, we added the variables Information Sharing (i.e., 1 if buyers disclosed the size of the bargaining pie to the sellers by disclosing their logistic costs, and 0 otherwise), Buyer-Cooperative Message (i.e., 1 if the buyers accompanied their first counteroffer with a message indicating their willingness to work with the seller to obtain a favorable deal for both negotiators, and 0 otherwise), and Abandon (i.e., 1 if buyers abandoned the negotiation without an agreement, and 0 otherwise). Overall, our results are robust to the inclusion of these additional control variables.
}

find that this factor is an important negative confounder and including it in the model is indispensable for observing the effects that we are interested in testing. ${ }^{19}$

\section{Conclusions and discussion}

In a buyer-seller context, this study explores to which degree buyers' relative bargaining power moderates the influence that the delay costs of the setting have on negotiation outcomes (i.e., duration of negotiations and bargaining profits). To explore this notion, we conduct a $2 \times 2$ between-subjects experiment simulating a buyer-seller sequential negotiation in which we manipulate buyers' relative bargaining power (equal or higher than sellers) and the delay costs of the bargaining setting (low or high). Consistent with our theoretical framework, findings indicate that: a) buyers' bargaining power moderates (i.e., decreases) the extent to which the delay costs reduce the initial bargaining gap (i.e., difference between the initial bargaining demands of sellers and buyers), and b) buyers' bargaining power moderates the indirect effect (via the initial bargaining gap and the duration of negotiations) that the delay costs of the setting exert on buyers' bargaining profits. Our findings indicate that the effect of bargaining power asymmetries in dyadic negotiations go beyond buyers' preference for using a more distributive approach (e.g., Van den Abbeele et al., 2009). More powerful buyers also tend to incorporate the delay costs of the setting to a lesser extent into their decision-making process. This finding has important implications for practitioners. For instance, when a negotiator is in a disadvantageous bargaining power position, she should not expect the powerful counterparty's behavior to be flexible as a result of other environmental factors, such as the delay costs. Therefore, to reach earlier agreements and reduce the delay costs, less powerful negotiators may try to make their more powerful partner more aware of the delay costs. Likewise, assuming that the delay costs are a continuous function of time, less powerful negotiators may reduce the total delay costs by starting negotiations earlier and/or providing prompt counteroffers when needed. Conversely, when a negotiator is in an advantageous bargaining power situation, she should objectively evaluate the situation in order to avoid making excessively risky or overconfident decisions that may lead to undesirable outcomes or may even compromise future interactions with her counterparty. In this matter, our results are somehow consistent with prior research indicating that agents with a favorable relative bargaining power position are more prone to taking risks (e.g., Jordan et al., 2011). In our specific context, as the delay costs of the setting increase, more powerful buyers have a higher risk of engaging in longer and less profitable negotiations. Therefore, more powerful buyers should want to make a more objective evaluation of the relevant factors in the negotiation environment (e.g., delay costs) to determine whether the distributive bargaining approach driven by having a relative bargaining power is the best strategy.

Our findings also suggest that the relation between our experimental treatments and bargaining profits is complex, and exploring only the direct effects may provide a somewhat limited picture of this relation. The delay costs of the setting are likely to have a direct effect on the bargaining profits because, ceteris paribus, the cost of extending negotiations is higher than in settings with lower delay costs. However, the delay costs also affect the bargaining profits by influencing negotiators' behavior and decisions about some important intermediate outcomes. Therefore, it is important to explore the indirect effects of the experimental treatments on bargaining profits (via the intermediate outcomes) in order to obtain a comprehensive picture of the influence of our experimental treatments. To exemplify this notion, based on the direct

\footnotetext{
19 The results of a non-tabulated analysis indicate that the interaction term between Buyer-Relative Bargaining Power and Delay Costs on Model 1 of Table 4 becomes non-significant (p-value=0.13) when Equal Monetary Payoff is not included as a control variable in the model.
} 


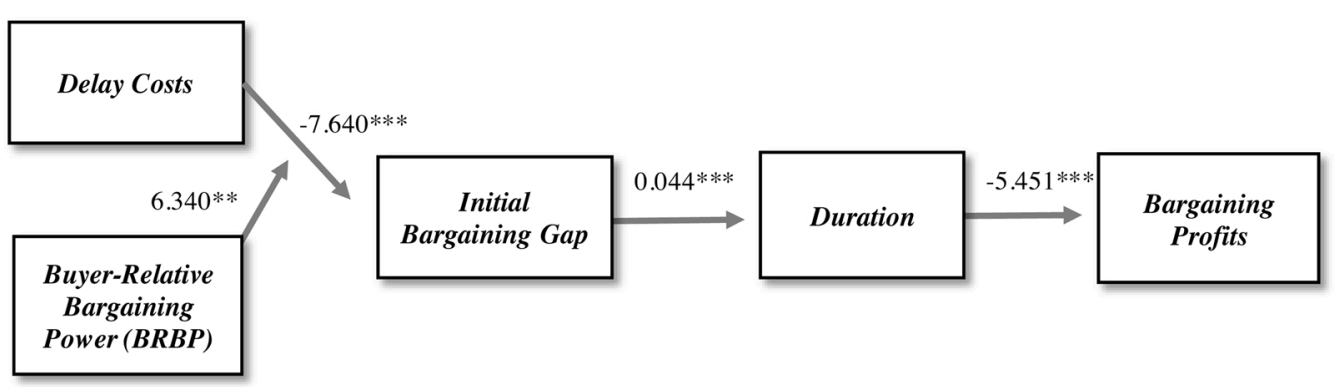

\begin{tabular}{|c|c|c|c|}
\hline \multirow[t]{2}{*}{ Hypotheses: } & \multirow[t]{2}{*}{$\begin{array}{c}\text { Model } \\
\text { Coeficient }\end{array}$} & \multicolumn{2}{|c|}{$\begin{array}{c}95 \% \text { Confidence } \\
\text { Interval }\end{array}$} \\
\hline & & $\mathbf{L L}$ & HL \\
\hline$H 1:(B B P \times D C) \rightarrow$ Initial Bargaining Gap & $6.340 * *$ & & \\
\hline H2: $($ BBP $x$ DC) $\rightarrow$ Initial Bargaining Gap $\rightarrow$ Duration & & 0.039 & 0.517 \\
\hline$D C \rightarrow$ Initial Bargaining Gap $\rightarrow$ Duration & & -0.519 & -0.151 \\
\hline H3: $($ BBP $x$ DC) $\rightarrow$ Initial Bargaining Gap $\rightarrow$ Duration $\rightarrow$ Bargaining Profits (-) & & -2.903 & -0.126 \\
\hline DC $\rightarrow$ Initial Bargaining Gap $\rightarrow$ Duration $\rightarrow$ Bargaining Profits $(+)$ & & 0.712 & 2.930 \\
\hline
\end{tabular}

Fig. 2. Shows a summary of the results of our analysis (presented in Table 4 ). *, **, *** indicate significance at $10 \%, 5 \%$ and $1 \%$, respectively.

effects only, we would conclude that buyers' bargaining power does not moderate the effect of the delay costs on the bargaining profits. However, the analysis of the indirect effects shows that the bargaining power moderates the relation between the delay costs of the setting and the bargaining profits by reducing the effect of the delay costs on the initial bargaining gap and the duration of negotiations. Based on these ideas, we consider that future behavioral research may benefit from exploring the indirect effects of the relations as this may help us to understand better the behavioral patterns relevant to the phenomenon of interest.

We consider that our findings may be applied to the study of the bargaining decisions made in other settings in which the timing and the power asymmetries are fundamental variables. For instance, our findings may provide new insights on the analysis of managers' answers to first offers by auditors (Cheng et al., 2017; Sanchez et al., 2007). Likewise, our results also open a new door to the design of bargaining settings where a planner has to set the negotiation conditions. A practical application would be the negotiation of transfer prices between the departments of the same firm. By analyzing the differences of power among the different departments, and knowing the reaction of more powerful ones, the main manager of a company could choose the most efficient delay costs system regarding her targets. In this way, the most powerful department could lose part of its resources as a consequence of its behavior, and CEOs could reallocate these resources to promote a fairer allocation of resources. Another example, extrapolating the previous example to the political economy, could be the relation between a state and two or more individual firms inside the same economy. In addition, our findings indicate that the EMP model may represent an important negative confounder that reduces the noise in the models and help us to observe the true association between our manipulations and the initial bargaining gap. Based on this idea, we consider that future research on negotiation behavior may benefit from taking into account the heuristic rule suggested by the EMP when conducting empirical testing. Finally, we would like to mention some limitations of our study. First, the participants in our study were undergraduates. This may raise some concerns about the generalizability of the results. However, we do not consider this to be a major limitation because, on one hand, economic theories are likely to apply in general and not only to older or graduated individuals (Croson, 2005), and on the other, although the participants' behavior in the laboratory may differ from that of a top executive (e.g., Levitt and List, 2007), the use of undergraduate students is a common practice in experimental managerial accounting research (e.g., Fisher et al., 2002; Drake and Haka, 2008; Maas et al., 2011; Guo et al., 2017). Second, we use a setting in which both bargainers face the same level of delay costs. This assumption may be natural if one considers the presence of efficient capital markets (Cramton, 1992). However, one may find examples in real life for which this condition does not hold. Analyzing how the difference in the discount rates among dyad members modifies negotiators' decisions could be an interesting topic for future accounting research. For instance, if buyers face higher delay costs and sellers face lower delay costs, the risk taken by more powerful buyers might be even higher because their power advantage may make them ignore that they are facing a seller who is facing lower costs of playing several rounds. Another potential limitation of our study is that, following prior research (i.e., Van den Abeele et al., 2009) we choose a fixed and rather low payment for the outside option. Although our results indicate that our manipulation was enough to make buyers feel powerful, this approach does not allow us to make any inference about the effect that "better" outside options may have on buyers' behavior. We leave this for future research. Finally, we develop this study using a very specific noncooperative bargaining setting. However, as explained in our theoretical framework (i.e., subsection 2.2), the proposed moderating effect of buyers' bargaining power on the relation between the delay costs of the setting and negotiation outcomes happens due to issues unrelated to the setting. Hence, we would expect the moderating effect of buyers' bargaining power on the delay cost of the setting to be similar in different settings. Nevertheless, prior research has shown that individuals' behavior is likely to diverge from theoretical expectations (e.g., Srivastava et al., 2000). Therefore, we consider that testing our theoretical framework in different settings, or testing other environmental factors influencing the proposed moderating effect of buyers' bargaining power, may be a potential venue for future research.

\section{Acknowledgments}

We would like to sincerely acknowledge our two reviewers for all their insightful feedback and suggestions during the review process. We would also like to thank our partner Jennifer Rontganger for her invaluable help during the successive stages in the development of this 
paper. This work was supported by the Spanish Ministry of Economy and Competitiveness under Grants ECO2013-45864-P and ECO2017-87514P; Community of Madrid (Grant S2015/HUM-3417 and Programa Excelencia para el Profesorado Universitario, convenio con Universidad Carlos III de Madrid, V Plan Regional de Investigación Científica e Innovación Tecnológica); and FEDER under Grant UNC315-EE-3636.

\section{References}

Anderson, C., Galinsky, A.D., 2006. Power, optimism, and risk-taking. Eur. J. Soc. Psychol. 36, 511-536. https://doi.org/10.1002/ejsp.324.

Arnold, M.C., 2015. The effect of superiors' exogenous constraints on budget negotiations. Account. Rev. 90, 31-57. https://doi.org/10.2308/accr-50864.

Backus, M., Blake, T., Larsen, B., Tadelis, S., 2020. Sequential bargaining in the field: evidence from millions of online bargaining interactions. Q. J. Econ. 135, 1319-1361. https://doi.org/10.1093/qje/qjaa003.

Blay, A., Douthit, J., Fulmer, B., 2019. Why don't people lie? Negative affect intensity and preferences for honesty in budgetary reporting. Manag. Account. Res. 42, 56-65. https://doi.org/10.1016/j.mar.2018.05.001.

Chang, L.J., Cheng, M.M., Trotman, K.T., 2013. The effect of outcome and process accountability on customer-supplier negotiations. Accounting, Organ. Soc. 38, 93-107. https://doi.org/10.1016/j.aos.2012.12.002.

Cheng, M.M., Tan, H.-T., Trotman, K.T., Tse, A., 2017. The impact of the timing of a prior year's auditor concessions on financial officers' judgments. Audit. A J. Pract. Theory 36, 43-62. https://doi.org/10.2308/ajpt-51517.

Cramton, P.C., 1992. Strategic delay in bargaining with two-sided uncertainty. Rev. Econ. Stud. 59, 205-225. https://doi.org/10.2307/2297934.

Croson, R., 2005. The method of experimental economics. Int. Negot. 10, 131-148. https://doi.org/10.1163/1571806054741100.

Cross, J.G., 1969. The Economics of Bargaining. Basic Books, New York.

De Dreu, C.K.W., 2003. Time pressure and closing of the mind in negotiation. Organ. Behav. Hum. Decis. Process. 91, 280-295. https://doi.org/10.1016/S0749-5978(03) 00022-0.

De Dreu, C.K.W., Van Kleef, G.A., 2004. The influence of power on the information search, impression formation, and demands in negotiation. J. Exp. Soc. Psychol. 40, 303-319. https://doi.org/10.1016/j.jesp.2003.07.004.

Drake, A.R., Haka, S.F., 2008. Does ABC information exacerbate hold-up problems in buyer-supplier negotiations? Account. Rev. 83, 29-60. https://doi.org/10.2308/ accr. 2008.83.1.29.

Emerson, R.M., 1962. Power-dependence relations. Am. Sociol. Rev. 27, 31-41. https:// doi.org/10.2307/2089716.

Emerson, R.M., 1976. Social exchange theory. Annu. Rev. Sociol. 2, 335-362. https:// doi.org/10.1146/annurev.so.02.080176.002003.

Fast, N.J., Gruenfeld, D.H., Sivanathan, N., Galinsky, A.D., 2009. Illusory control: a generative force behind power's far-reaching effects. Psychol. Sci. 20, 502-508. https://doi.org/10.1111/j.1467-9280.2009.02311.x.

Fast, N.J., Sivanathan, N., Mayer, N.D., Galinsky, A.D., 2012. Power and overconfident decision-making. Organ. Behav. Hum. Decis. Process. 117, 249-260. https://doi. org/10.1016/j.obhdp.2011.11.009.

Fisher, J.G., Maines, L.A., Peffer, S.A., Sprinkle, G.B., 2002. Using budgets for performance evaluation: effects of resource allocation and horizontal information asymmetry on budget proposals, budget slack, and performance. Account. Rev. 77, 847-865. https://doi.org/10.2308/accr.2002.77.4.847.

Fréchette, G.R., 2012. Session-effects in the laboratory. Exp. Econ. 15, 485-498. https:// doi.org/10.1007/s10683-011-9309-1.

Galinsky, A.D., 2004. Should you make the first offer? Negotiation 7, 1-4.

Galinsky, A.D., Magee, J.C., Gruenfeld, D.H., Whitson, J.A., Liljenquist, K.A., 2008 Power reduces the press of the situation: implications for creativity, conformity, and dissonance. J. Pers. Soc. Psychol. https://doi.org/10.1037/a0012633.

Giebels, E., De Dreu, C.K.W., Van De Vliert, E., 2000. Interdependence in negotiation: effects of exit options and social motive on distributive and integrative negotiation. Eur. J. Soc. Psychol. 30, 255-272. https://doi.org/10.1002/(SICI)1099-0992 (200003/04)30:2<255::AID-EJSP991>3.0.CO;2-7.

Grossman, S.J., Perry, M., 1986. Sequential bargaining under asymmetric information. J. Econ. Theory 39, 120-154. https://doi.org/10.1016/0022-0531(86)90023-2.

Guo, L., Libby, T., Liu, X..(Kelvin), 2017. The effects of vertical pay dispersion: experimental evidence in a budget setting. Contemp. Account. Res. 34, 555-576. https://doi.org/10.1111/1911-3846.12245.
Harrison, G.W., Lau, M.I., Elisabet Rutström, E., 2009. Risk attitudes, randomization to treatment, and self-selection into experiments. J. Econ. Behav. Organ. 70, 498-507. https://doi.org/10.1016/j.jebo.2008.02.011.

Hayes, A.F., 2017. Introduction to Mediation, Moderation, and Conditional Process Analysis: a Regression-based Approach. Guilford Publications.

Heckman, J.J., Smith, J.A., 1995. Assessing the case for social experiments. J. Econ. Perspect. 9, 85-110. https://doi.org/10.1257/jep.9.2.85.

James, H.S., Cohen, J.P., 2004. Does ethics training neutralize the incentives of the prisoner's dilemma? Evidence from a classroom experiment. J. Bus. Ethics 50, 53-61. https://doi.org/10.1023/B:BUSI.0000020869.42655.f4.

Jordan, J., Sivanathan, N., Galinsky, A.D., 2011. Something to lose and nothing to gain: the role of stress in the interactive effect of power and stability on risk taking. Adm. Sci. Q. 56, 530-558. https://doi.org/10.1177/0001839212441928.

Levitt, S.D., List, J.A., 2007. What do laboratory experiments measuring social preferences reveal about the real world? J. Econ. Perspect. 21, 153-174. https://doi. org/10.1257/jep.21.2.153.

Lourenço, S.M., 2020. Do self-reported motivators really motivate higher performance? Manag. Account. Res. 47, 100676 https://doi.org/10.1016/j.mar.2019.100676.

Lourenço, S.M., Greenberg, J.O., Littlefield, M., Bates, D.W., Narayanan, V.G., 2018. The performance effect of feedback in a context of negative incentives: evidence from a field experiment. Manag. Account. Res. 40, 1-14. https://doi.org/10.1016/j. mar.2018.01.002.

Maas, V.S., van Rinsum, M., Towry, K.L., 2011. In search of informed discretion: an experimental investigation of fairness and trust reciprocity. Account. Rev. 87, 617-644. https://doi.org/10.2308/accr-10205.

Masschelein, S., Cardinaels, E., Van den Abbeele, A., 2012. ABC information, fairness perceptions, and interfirm negotiations. Account. Rev. 87, 951-973. https://doi.org/ 10.2308/accr-10214.

McCracken, S., Salterio, S.E., Schmidt, R.N., 2011. Do managers intend to use the same negotiation strategies as partners? Behav. Res. Account. 23, 131-160. https://doi. org/10.2308/bria.2011.23.1.131.

Pettypiece, S., Townsend, M., 2015. Wal-Mart's Suppliers Are Finally Fighting Back [WWW Document]. Bloomberg. URL. https://www.bloomberg.com/news/articles/ 2015-09-11/wal-mart-sparks-battle-with-suppliers-over-margin-squeezing-fees.

Pinkley, R.L., Neale, M.A., Bennett, R.J., 1994. The impact of alternatives to settlement in dyadic negotiation. Organ. Behav. Hum. Decis. Process. 57, 97-116. https://doi. org/10.1006/obhd.1994.1006.

Sanchez, M.H., Agoglia, C.P., Hatfield, R.C., 2007. The effect of auditors' use of a reciprocity-based strategy on auditor-client negotiations. Account. Rev. 82, 241-263. https://doi.org/10.2308/accr.2007.82.1.241.

Schloetzer, J.D., 2012. Process integration and information sharing in supply chains. Account. Rev. 87, 1005-1032. https://doi.org/10.2308/accr-10216.

Smith, D.L., Pruitt, D.G., Carnevale, P.J.D., 1982. Matching and mismatching: the effect of own limit, other's toughness, and time pressure on concession rate in negotiation. J. Pers. Soc. Psychol. 42, 876-883. https://doi.org/10.1037/0022-3514.42.5.876.

Srivastava, J., 2001. The role of inferences in sequential bargaining with one-sided incomplete information: some experimental evidence. Organ. Behav. Hum. Decis. Process. 85, 166-187. https://doi.org/10.1006/obhd.2000.2936.

Srivastava, J., Chakravarti, D., 2009. Channel negotiations with information asymmetries: contingent influences of communication and trustworthiness reputations. J. Mark. Res. 46, 557-572. https://doi.org/10.1509/jmkr.46.4.557.

Srivastava, J., Chakravarti, D., Rapoport, A., 2000. Price and margin negotiations in marketing channels: an experimental study of sequential bargaining under one-sided uncertainty and opportunity cost of delay. Mark. Sci. 19, 163-184. https://doi.org/ 10.1287/mksc.19.2.163.11806.

Thompson, L., 2004. The Mind and Heart of the Negotiator, 3rd ed. Prentice Hall, Upper Saddle River, NJ.

Van den Abbeele, A., Roodhooft, F., Warlop, L., 2009. The effect of cost information on buyer-supplier negotiations in different power settings. Accounting, Organ. Soc. 34, 245-266. https://doi.org/10.1016/j.aos.2008.05.005.

White, S.B., Neale, M.A., 1994. The role of negotiator aspirations and settlement expectancies in bargaining outcomes. Organ. Behav. Hum. Decis. Process. 57, 303-317. https://doi.org/10.1006/obhd.1994.1017.

Wolfe, R.J., Mcginn, K.L., 2005. Perceived relative power and its influence on negotiations. Gr. Decis. Negot. 14, 3-20. https://doi.org/10.1007/s10726-0053873-8.

Zwick, R., Chen, X.-P., 1999. What price fairness? A bargaining study. Manage. Sci. 45, 804-823. https://doi.org/10.1287/mnsc.45.6.804. 